Indeed, the current classification moves to the right direction by adopting a clinically meaningful way of thinking and avoiding unnecessary pathophysiological implications; $\mathrm{PH}$ owing to left heart disease (Group 2) and chronic thromboembolism (Group 4) are good examples. In this context, sarcoidosis, PLCH and LAM (Group 5.2) represent disorders that, according to the current evidence, are associated with $\mathrm{PH}$ mainly due to lung involvement and, therefore, we propose their inclusion in the third category ( $\mathrm{PH}$ owing to lung disease and/or hypoxia) in any future classification scheme.

\section{Tsangaris*, S. Orfanos* and D. Bouros"}

2nd Critical Care Dept, Attikon University Hospital, Athens, and "Dept of Pneumonology, Medical School, Democritus University of Thrace, Komotini, Greece.

Correspondence: I. Tsangaris, 2nd Dept of Critical Care Medicine, University Hospital Attikon, Medical School, University of Athens, 1 Rimini Str, Athens 12462, Greece, E-mail: itsagkaris@med.uoa.gr

\section{REFERENCES}

1 Galiè N, Hoeper MM, Humbert M, et al. Guidelines for the diagnosis and treatment of pulmonary hypertension. The Task Force for the Diagnosis and Treatment of Pulmonary Hypertension of the European Society of Cardiology (ESC) and the European Respiratory Society (ERS), endorsed by the International Society of Heart and Lung Transplantation (ISHLT). Eur Respir J 2009; 34: 1219-1263.

2 Travis WD, King TE, Bateman ED, et al. ATS/ERS international multidisciplinary consensus classification of idiopathic interstitial pneumonias. General principles and recommendations. Am J Respir Crit Care Med 2002; 165: 277-304.

3 Baughman RP, Teirstein AS, Judson MA, et al. Case Control Etiologic Study of Sarcoidosis (ACCESS) research group. Clinical characteristics of patients in a case control study of sarcoidosis. Am J Respir Crit Care Med 2001; 164: 1885-1889.

4 Nunes H, Humbert M, Capron F, et al. Pulmonary hypertension associated with sarcoidosis: mechanisms, haemodynamics and prognosis. Thorax 2006; 61: 68-74.

5 Behr J, Ryu JH. Pulmonary hypertension in interstitial lung disease. Eur Respir J 2008; 31: 1357-1367.

\title{
Predicting persistence of wheezing: one algorithm does not fit all
}

\section{From the authors:}

ScOTT et al. [1] have commented, in the light of outcomes of their "Isle of Wight Birth Cohort study" (IoWBC) [2, 3], on our findings on the risk factors for asthma in the Multicentre Allergy Study (MAS) birth cohort study [4]. We agree that the two studies lead to similar conclusions in regard to early origins of persistent wheezing, heterogeneity of childhood wheezing and the relevance of an atopic background. In addition, we followed their suggestion to build a prognostic score in accordance with the IoWBC [3] and to test its performance in the MAS database. Here we report the results of our analysis.

The IWBC prognostic algorithm comprises four risk factors: a family history of asthma; recurrent chest infections in infancy; absence of nasal symptoms at age $1 \mathrm{yr}$; and atopic sensitisation at age 4 yrs [3]. To make the data of the two cohorts comparable, we reduced our longitudinal study with followups every year to the four time points of the Isle of Wight Study: age 1, 2, 4 and 10 yrs. Due to missing values, this reduction resulted in a fairly smaller population sample $(n=765)$; therefore we increased the older age group by 8 and 9 yr olds and obtained a proportion of examined children similar to the one obtained in the IoWBC. The parameters we used were quite similar, although not identical, to those used in the IoWBC study (table 1). The frequency distribution of the risk score in the MAS cohort was similar to the one observed in the IoWBC; however, only three children with early wheezing had a risk score of 4 (table 2). A cut-off to predict persistent wheeze in the MAS cohort was therefore placed at a risk score of $\geqslant 3$. The positive predictive value (PPV) we obtained with this cut-off was 0.65 (95\% CI 0.44-0.82) (table 3). Interestingly, when adopting a cut-off of 3 , the PPV in the IoWBC study was 0.68 , i.e. almost the same as the one obtained in the MAS cohort (table 3) [3].

On this basis we may conclude, as proposed by ScOTT et al. [1], that the IoWBC score can be a starting point in developing a clinically relevant predictive tool. Preventive measures should not be advised to children whose wheezing is likely to undergo spontaneous remission; therefore, a high PPV is desirable. On this basis, we feel that an algorithm based on early wheezing, sensitisation to mites and elevated allergen exposure, might be also clinically useful because it resulted in a better prediction in the MAS cohort (PPV 0.83). On the other hand, a third algorithm, based on the presence of atopic eczema, immunoglobulin (Ig)E sensitisation to food allergens and specific polymorphisms of the filaggrin gene, was able to predict another subset of asthmatic children of the MAS cohort with a PPV and equal to 1.00 (95\% CI 65-100) [5]. Given the great heterogeneity of mechanisms and risk factors for wheezing disorders, multiple algorithms are likely necessary to predict, with enough confidence, persistence of wheezing in the children with early wheezing. 
TABLE 1 Population examined, definitions and multivariate analysis for the persistence of early life wheezing

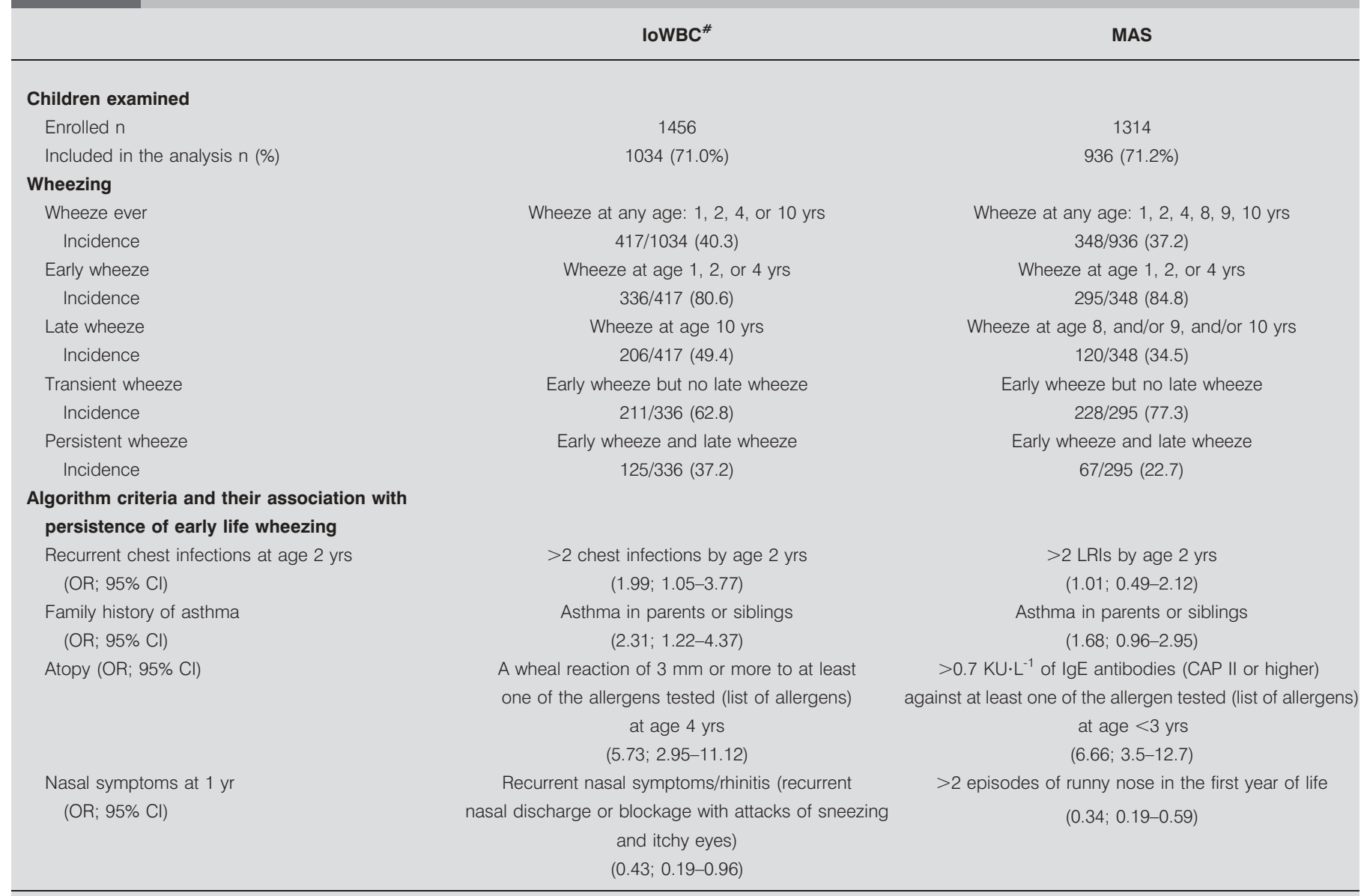

Data are presented as n/N (\%), unless otherwise stated. loWBC : Isle of Wight Birth Cohort study; MAS: Multicentre Allergy Study; Ig: immuglobulin. " : data as reported by KURUKULAARATCHY et al. [3].

A second point raised by SCOTT et al. [1] concerns the role of tobacco smoke and the genetic background in the determination of wheezing persisting up to puberty. The role of smoke and genetic predisposition in the MAS cohort has been recently published [6]. This study demonstrated that among children with two allergic parents, a mother who

\section{TABLE 2 Prevalence and risk of wheezing outcome according to risk scoring system (table 1)}

\begin{tabular}{|c|c|c|c|c|c|c|c|c|}
\hline \multirow{3}{*}{$\begin{array}{l}\text { Risk } \\
\text { score } \\
\text { strata }\end{array}$} & \multicolumn{4}{|c|}{ loWBC $\#$} & \multicolumn{4}{|c|}{ MAS } \\
\hline & \multicolumn{2}{|c|}{ Wheezing outcome for each score } & \multirow[t]{2}{*}{ p-value } & \multirow[t]{2}{*}{ OR (95\% Cl) } & \multicolumn{2}{|c|}{ Wheezing outcome for each score } & \multirow[t]{2}{*}{$\mathrm{p}$-value } & \multirow[t]{2}{*}{ OR $(95 \% \mathrm{Cl})$} \\
\hline & Persistent & Transient & & & Persistent & Transient & & \\
\hline 0 & 2/10 (20.0) & $8 / 10(80.0)$ & 0.324 & $0.4(0.08-1.83)$ & $11 / 97(11.3)$ & $86 / 97(88.7)$ & 0.001 & $0.32(0.16-0.65)$ \\
\hline 2 & $32 / 101(31.7)$ & $69 / 101(68.3)$ & 0.058 & $0.6(0.36-1.02)$ & 15/53 (28.3) & $38 / 53(71.7)$ & 0.283 & $1.44(0.74-2.82)$ \\
\hline 3 & $42 / 64(65.6)$ & 22/64 (34.4) & $<0.001$ & $4.5(2.46-8.19)$ & $12 / 20(60.0)$ & $8 / 20(40.0)$ & $<0.001^{\circ}$ & $6.00(2.34-15.39)$ \\
\hline 4 & 10/12 (83.3) & $2 / 12(16.7)$ & 0.002 & $8.7(1.85-40.38)$ & $3 / 3(100.0)$ & $0 / 3(0.0)$ & $0.011^{\bullet}$ & \\
\hline
\end{tabular}

Data are presented as n/N (\%), unless otherwise stated. IOWBC : Isle of Wight Birth Cohort study; MAS: Multicentre Allergy Study. ${ }^{\#}$ : data as reported by KuRUKULAARATCHY et al. [3]; ": comparisons are with Fischer's exact test where indicated by low cell counts. 


\begin{tabular}{|c|c|c|c|c|c|c|c|c|c|c|c|}
\hline TABLE 3 & $\begin{array}{l}\text { Perform } \\
\text { studies }\end{array}$ & ance for rist & scorin & systen & the Is & of Wight $B$ & Cohort (lo & ) and & Iticentre All & y Stuc & MAS) \\
\hline \multirow{2}{*}{$\begin{array}{l}\text { Risk } \\
\text { score } \\
\text { strata }\end{array}$} & \multicolumn{5}{|c|}{ loWBC" } & \multicolumn{6}{|c|}{ MAS } \\
\hline & Sensitivity & Specificity & PPV & NPV & LR+ & Sensitivity & Specificity & PPV & $\begin{array}{l}95 \% \mathrm{Cl} \\
\text { for PPV }\end{array}$ & NPV & $\mathrm{LR}+{ }^{5}$ \\
\hline$>1$ & 0.979 & 0.051 & 0.396 & 0.8 & 1.032 & 0.836 & 0.377 & 0.283 & $0.248-0.308$ & 0.887 & 1.342 \\
\hline$>2$ & 0.845 & 0.404 & 0.475 & 0.808 & 1.418 & 0.448 & 0.798 & 0.395 & $0.303-0.487$ & 0.831 & 2.219 \\
\hline$>3$ & 0.525 & 0.846 & 0.684 & 0.737 & 3.409 & 0.224 & 0.965 & 0.652 & $0.439-0.823$ & 0.809 & 6.381 \\
\hline 4 & 0.103 & 0.987 & 0.833 & 0.639 & 7.923 & 0.045 & 1.000 & 1.000 & & 0.781 & \\
\hline
\end{tabular}

smoked regularly significantly increased the odds for allergic sensitisation (adjusted OR 4.8, 95\% CI 1.3-18.2) and wheezing (adjusted OR 5.7, 95\% CI 1.7-19.0) in her child compared with children who were never exposed. By contrast, maternal smoking had no effects in children without allergic parents. The results of the MAS cohort study therefore agree also in this respect with those obtained by IoWBC study and support the existence of gene-by-environment interaction (in our example "atopic heredity-by-maternal smoke" interaction) in the inception of asthma.

Similarities in the IoWBC and the MAS studies show that our research toward understanding the origins of asthma, by following the footsteps left by children developing persistent wheezing, is on the right track. We are probably starting to make good use of another Sherlock Holmes' famous aphorism: "In solving a problem of this sort, the grand thing is to be able to reason backward" [7].

\section{P.M. Matricardi*, S. Illi", T. Keil ${ }^{\mp}$, P. Wagner*, U. Wahn* and S. Lau*}

Dept of Paediatric Pneumology and Immunology, "Institute for Social Medicine, Epidemiology and Health Economics, Charité University Medical Centre, Berlin, and \#Dr. von Hauner University Children's Hospital, Ludwig Maximilian University, Munich, Germany.
Correspondence: P.M. Matricardi, Dept of Paediatric Pneumology and Immunology, Charité University Medical Centre, Berlin, Germany. E-mail: paolo.matricardi@charite.de

Statement of Interest: None declared

\section{REFERENCES}

1 Scott M, Kurukulaaratchy RJ, Raza A, et al. Understanding the nature and outcome of childhood wheezing. Eur Respir J 2009; 33: 700-701.

2 Matricardi PM, Illi S, Gruber C, et al. Wheezing in childhood: incidence, longitudinal patterns and factors predicting persistence. Eur Respir J 2008; 32: 585-592.

3 Kurukulaaratchy RJ, Fenn MH, Waterhouse LM, et al. Characterization of wheezing phenotypes in the first 10 years of life. Clin Exp Allergy 2003; 33: 573-578.

4 Kurukulaaratchy RJ, Matthews S, Holgate ST, et al. Predicting persistent disease among children who wheeze during early life. Eur Respir J 2003; 22: 767-771.

5 Marenholz I, Kerscher T, Bauerfeind A, et al. An interaction between filaggrin mutations and early food sensitization improves the prediction of childhood asthma. J Allergy Clin Immunol. 2009; 123: 911-916.

6 Keil T, Lau S, Roll S, et al. Maternal smoking increases risk of allergic sensitization and wheezing only in children with allergic predisposition: longitudinal analysis from birth to 10 years. Allergy 2009; 64: 445-451.

7 Conan Doyle A. A Study in Scarlet. The Penguin Complete Sherlock Holmes. London, Penguin Books, 1981; p. 83.

DOI: 10.1183/09031936.00163709 